\title{
Primary breast diffuse large B-cell lymphoma: a population- based study from 1975 to 2014
}

\author{
Yijun Jiaa ${ }^{1,2,3}$, Chenbo Sun ${ }^{1,2,3}$, Zebing Liu ${ }^{1,2,3,4}$, Weige Wang ${ }^{1,2,3}$ and Xiaoyan Zhou ${ }^{1,2,3}$ \\ ${ }^{1}$ Department of Pathology, Fudan University Shanghai Cancer Center, Shanghai 200032, China \\ ${ }^{2}$ Department of Oncology, Shanghai Medical College, Fudan University, Shanghai 200032, China \\ ${ }^{3}$ Institute of Pathology, Fudan University, Shanghai 200032, China \\ ${ }^{4}$ Department of Pathology, Renji Hospital, School of Medicine, Shanghai Jiaotong University, Shanghai 200127, China
}

Correspondence to: Xiaoyan Zhou, email: xyzhou100@163.com

Keywords: breast lymphoma, diffuse large B-cell lymphoma, incidence, survival

Received: June 29, 2017 Accepted: September 20, 2017 Published: December 08, 2017

Copyright: Jia et al. This is an open-access article distributed under the terms of the Creative Commons Attribution License 3.0 (CC BY 3.0), which permits unrestricted use, distribution, and reproduction in any medium, provided the original author and source are credited.

\section{ABSTRACT}

Primary breast diffuse large B-cell lymphoma (DLBCL) is a rare non-Hodgkin's Iymphoma with limited data. In this study, a population-based study of primary breast DLBCL in the United States was performed to determine its incidence trends, prognostic factors, survival, the role of surgery as well as the comparison with nodal DLBCL. 1021 patients diagnosed with breast DLBCL were identified in the Surveillance, Epidemiology, and End Results (SEER) cancer registries from 19732014. The incidence of both breast and nodal DLBCL increased over time. Patients with breast DLBCL were older, mainly women, diagnosed at earlier stages and had lower prevalence in white and black races compared with nodal DLBCL. Multivariate analysis revealed older age ( $\geq 70$ years old) and advanced stage as independent predictors of worse OS. Independent predictor of better DSS were younger age $(<70$ years old), early stage and diagnosis after 2000 . When analyzed according to age, stage, race, tumor laterality and year of diagnosis, the overall survival did not benefit from surgery except in patients diagnosed between 2001-2010 and the surgery rate decreased overtime. Compared with nodal DLBCL, breast DLBCL patients exhibited a better outcome. In conclusion, breast $D L B C L$ is a rare tumor with increasing incidence and improved survival over the last four decades. The introduction of rituximab seems to improve the outcome of breast DLBCL. Further studies are needed to advance our understanding of breast DLBCL and optimize the treatment strategy.

\section{INTRODUCTION}

Breast is a rare site of extranodal involvement of lymphoma. Breast lymphoma represents approximately $0.5 \%$ of breast malignant neoplasms and between $1.7-2.2 \%$ of extranodal lymphoma [1,2]. It was first described in 1972 by Wiseman and Liao [3] in a group of 31 patients diagnosed between 1951 and 1970. They defined it as the infiltration of breast tissue by lymphoma with or without regional lymphnode in patients without a history of prior nodal or extranodal lymphoma and systemic diseases at the time of diagnosis. The frequent clinical presentation of primary breast lymphoma is painless palpable mass which is similar to that of breast cancer. The infrequent presentation includes skin edema [4], erythema [4-6] and retraction [7]. Primary breast lymphoma is usually non-Hodgkin's B-cell type, which accounts for about half of breast lymphomas, and the most frequent subtype is diffuse large B-cell lymphoma (DLBCL) [8-12].

As this breast malignancy is rare, there is limited information about its epidemiology and outcome and how it compares with primary nodal diffuse large B-cell lymphoma still remains unknown. Our current knowledge about breast DLBCL is based on anecdotal reports and retrospective studies with small numbers of patients. As a result, clinicians have little prospective data to guide optimal treatment. 
The treatment options for primary breast lymphoma vary broadly including surgical intervention, chemotherapy and radiotherapy [13]. However, the optimal management of patients with breast lymphoma remains unclear and controversial. Chemotherapy is the mainstay of therapy based on the success of chemotherapy in the treatment of nodal and other extranodal non-Hodgkin's lymphomas. Mastectomy for primary breast lymphoma is not wellsupported because it shows neither improved survival nor reduced risk of recurrence [9, 11, 14]. The role of radiotherapy has never been explored prospectively. One of the largest studies of breast DLBCL was reported by Jennings WC et al. [14], and they searched several databases and reviewed 92 articles in which patient-specific treatment and follow-up information were included, to determine the best treatment strategies for primary breast lymphoma. In that study, 465 acceptable patients reported from 1972 through 2005 were included. The study showed that nodal status predicts survival and outcome and guided optimal use of radiation and chemotherapy.

The Surveillance, Epidemiology, and End Results (SEER) database [15] is a useful resource for analyzing rare malignancies like primary breast lymphoma in settings for which prospective data or trials are limited. The main purpose of this retrospective study based on the SEER database is to provide the best available information to improve understanding of primary breast lymphoma. In this study, we examined the incidence and survival trends of breast DLBCL and compared characteristics between patients with breast and nodal DLBCL. This study also revealed prognostic factors of breast DLBCL, the effect of surgery and the potential impact of the introduction of rituximab.

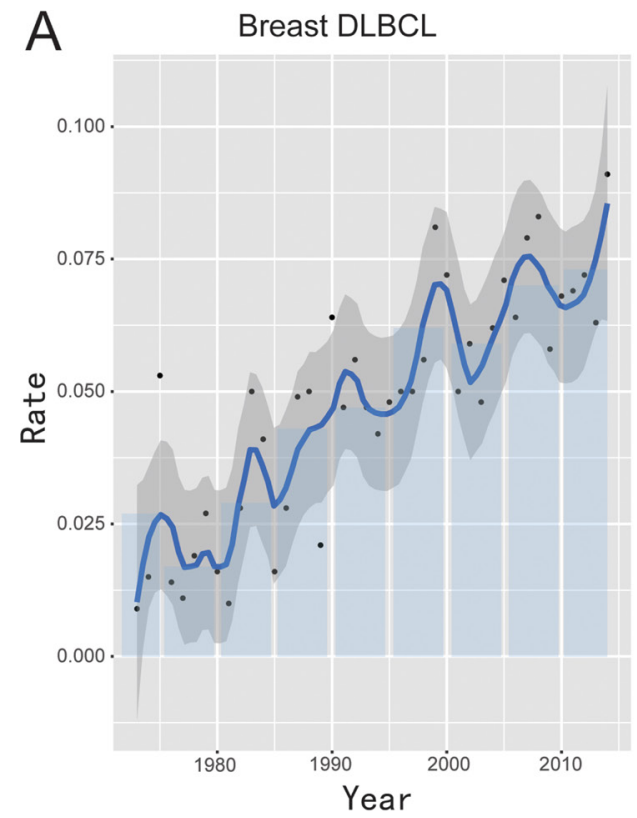

\section{RESULTS}

\section{Incidence of breast DLBCL}

The overall incidence rate of breast DLBCL was approximately 0.052 per 100,000 (adjusted to the 2000 standard US population). The overall cancer incidence rate in breast lymphoma increased from 0.03 per 100,000 people in 1973 to 1990 to 0.073 in 2011 to 2014, with a significant trend toward increasing incidence for breast DLBCL $(\mathrm{APC}=1.738 ; 95 \% \mathrm{CI}=1.9-3.6, P<0.01)$. Figure $1 \mathrm{~A}$ and Table 1 illustrated long-term trends in incidence rates for breast DLBCL.

Analysis by race showed that blacks have the lowest incidence $(0.032$ per 100,000$)$. While the highest incidence rate was observed in American Indians, Alaskan natives, and Asian/Pacific Islanders (0.082 per 100,000). Incidence rates of whites were between these two groups. For whites, the incidence of breast DLBCL increased at an APC of $3.0(95 \% \mathrm{CI}=2.1-3.8 ; P<0.01)$ and there was a statistically significant increase from 2001 to 2005 , with an APC of 14.6 (95\% CI $=1.4-29.6, P<0.01)$. Among age groups, the incidence rate of breast DLBCL was higher among patients of $\geq 70$ years old $(0.314$ per $100,000)$ compared with that of patients with the age of $<$ 70 years old (0.026 per 100,000). For individuals aged 70 years or older, a statistically significant increase in breast DLBCL incidence could be observed from 1996 to 2000 and the APC was 17.7 (95\% CI $=3.9-33.4, P<0.01)$. When analyzed by Ann Arbor Stage, the incidence rate for breast DLBCL diagnosed at stage I was 0.029, while the incidence rate for patients with stage II was 0.008 . For females, the incidence rate for breast DLBCL was

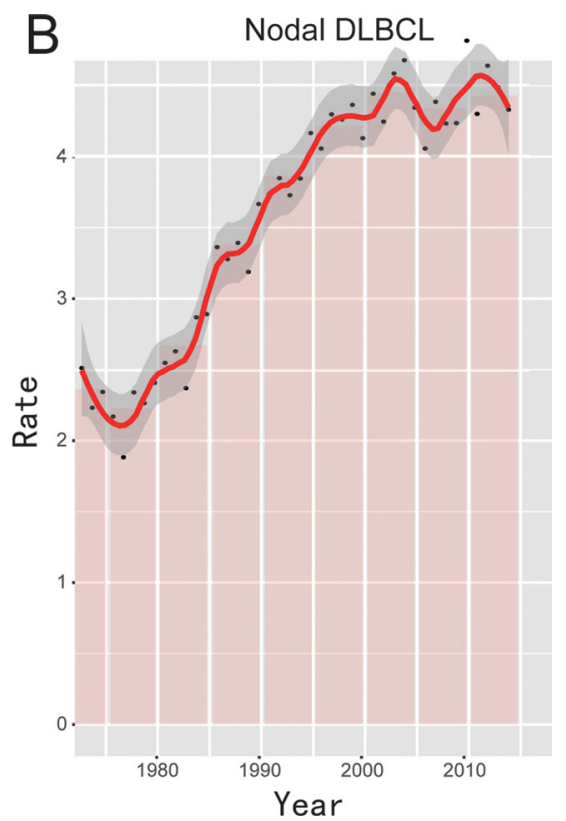

Figure 1: Overall incidence of breast DLBCL and nodal DLBCL from 1973 to 2013 adjusted to the 2000 standard US population. 
Table 1: Incidence Trends for Breast DLBCL and Nodal DLBCL from 1973-2014

\begin{tabular}{|c|c|c|c|c|c|c|c|c|c|c|c|c|c|c|}
\hline & \multirow{2}{*}{\multicolumn{2}{|c|}{ Overall Trend }} & \multirow{2}{*}{\multicolumn{2}{|c|}{$\begin{array}{c}\text { Trend } 1 \\
(1973-1990)\end{array}$}} & \multirow{2}{*}{\multicolumn{2}{|c|}{$\begin{array}{c}\text { Trend } 2 \\
(1991-1995)\end{array}$}} & \multirow{2}{*}{\multicolumn{2}{|c|}{$\begin{array}{c}\text { Trend 3 } \\
(1996-2000)\end{array}$}} & \multirow{2}{*}{\multicolumn{2}{|c|}{$\begin{array}{c}\text { Trend } 4 \\
(2001-2005)\end{array}$}} & \multirow{2}{*}{\multicolumn{2}{|c|}{$\begin{array}{c}\text { Trend } 5 \\
(2006-2010)\end{array}$}} & \multirow{2}{*}{\multicolumn{2}{|c|}{$\begin{array}{c}\text { Trend } 6 \\
\text { (2011-2014) }\end{array}$}} \\
\hline & & & & & & & & & & & & & & \\
\hline & Rate & APC & Rate & APC & Rate & APC & Rate & APC & Rate & APC & Rate & APC & Rate & APC \\
\hline \multicolumn{15}{|c|}{ Breast DLBCL } \\
\hline Overall & 0.0522 & $2.7^{*}$ & 0.03 & 5.0 & 0.048 & -2.6 & 0.062 & 13.1 & 0.059 & 8.2 & 0.07 & -1.9 & 0.073 & 8.5 \\
\hline \multicolumn{15}{|l|}{ Age } \\
\hline$<70$ & 0.026 & NA & 0.016 & NA & 0.019 & 0.02 & 0.03 & 7.4 & 0.032 & 0.28 & 0.033 & -3.0 & 0.035 & -4.6 \\
\hline$\geq 70$ & 0.314 & NA & 0.171 & NA & 0.327 & -5.3 & 0.378 & $17.7^{*}$ & 0.321 & 14.3 & 0.44 & -0.8 & 0.451 & 20.2 \\
\hline \multicolumn{15}{|l|}{ Race } \\
\hline White & 0.05 & $3.0^{*}$ & 0.029 & 3.2 & 0.045 & -0.5 & 0.06 & 8.2 & 0.053 & $14.6^{*}$ & 0.075 & -1.3 & 0.073 & 11.2 \\
\hline Black & 0.032 & NA & 0.01 & NA & 0.018 & NA & 0.035 & NA & 0.056 & -22.5 & 0.045 & NA & 0.034 & NA \\
\hline Other & 0.082 & NA & 0.06 & NA & 0.089 & NA & 0.1 & NA & 0.089 & -0.8 & 0.061 & -12.2 & 0.097 & 6.2 \\
\hline \multicolumn{15}{|l|}{ sex } \\
\hline Female & 0.087 & NA & 0.052 & NA & 0.078 & 2.3 & 0.105 & 11.7 & 0.104 & 5.5 & 0.115 & -1.6 & 0.122 & 10.1 \\
\hline Male & 0.007 & NA & 0.002 & NA & 0.004 & NA & 0.006 & NA & 0.001 & NA & 0.016 & NA & 0.015 & -9.1 \\
\hline \multicolumn{15}{|l|}{ Stage } \\
\hline I & 0.029 & NA & 0.013 & NA & 0.027 & 5.0 & 0.043 & 13.6 & 0.036 & 10.2 & 0.038 & -16.1 & 0.038 & 17.8 \\
\hline II & 0.008 & NA & 0.002 & NA & 0.007 & NA & 0.01 & -0.3 & 0.012 & 2.9 & 0.012 & 12.2 & 0.015 & 17.1 \\
\hline \multicolumn{15}{|c|}{ Nodal DLBCL } \\
\hline Overall & 3.762 & $1.7^{*}$ & 2.739 & $3.2^{*}$ & 3.862 & 2.3 & 4.216 & 0.5 & 4.453 & 0.5 & 4.341 & 3.2 & 4.43 & $-0.2-$ \\
\hline \multicolumn{15}{|l|}{ Age } \\
\hline$<70$ & 2.185 & $1.5^{*}$ & 1.637 & $3.1^{*}$ & 2.409 & 2.2 & 2.505 & -0.1 & 2.538 & -0.4 & 2.409 & 1.6 & 2.471 & -1.6 \\
\hline$\geq 70$ & 19.297 & $2.0^{*}$ & 13.601 & $3.3^{*}$ & 18.176 & 2.3 & 21.073 & 1.3 & 23.33 & 1.4 & 23.385 & $4.9^{*}$ & 23.739 & 1.2 \\
\hline \multicolumn{15}{|l|}{ Race } \\
\hline White & 3.926 & $1.8^{*}$ & 2.882 & $3.4^{*}$ & 4.104 & 1.8 & 4.448 & 0.7 & 4.667 & 0.6 & 4.491 & 2.8 & 4.697 & 0.0 \\
\hline Black & 2.79 & $2.5^{*}$ & 1.688 & $4.3^{*}$ & 2.515 & 9.8 & 3.015 & -3.2 & 3.509 & 5.3 & 3.439 & $4.1^{*}$ & 3.469 & 2.7 \\
\hline Other & 2.837 & $1.9^{*}$ & 1.815 & -0.3 & 2.539 & 7.6 & 2.875 & 3.7 & 3.118 & -2.9 & 3.628 & 4.6 & 3.081 & -5.0 \\
\hline \multicolumn{15}{|l|}{ Sex } \\
\hline Female & 4.601 & $1.5^{*}$ & 2.359 & $2.3^{*}$ & 3.24 & 3.2 & 3.487 & -0.6 & 3.634 & 0.3 & 3.521 & 2.9 & 3.544 & 0.1 \\
\hline Male & 3.101 & $1.9^{*}$ & 3.227 & $4.0^{*}$ & 4.608 & 1.5 & 5.108 & 1.6 & 5.487 & 1.0 & 5.355 & 3.3 & 5.515 & -0.7 \\
\hline \multicolumn{15}{|l|}{ Stage } \\
\hline I & 0.637 & NA & 0.305 & NA & 0.887 & 1.6 & 0.919 & -0.9 & 0.921 & -1.9 & 0.688 & -0.2 & 0.64 & -4.0 \\
\hline II & 0.593 & NA & 0.273 & NA & 0.63 & 5.6 & 0.758 & 2.1 & 0.805 & 0.9 & 0.799 & 0.6 & 0.771 & -3.6 \\
\hline III & 0.666 & NA & 0.215 & NA & 0.663 & 0.8 & 0.781 & 4.8 & 0.891 & $6.2^{*}$ & 0.972 & 4.0 & 1.129 & 2.5 \\
\hline IV & 1.286 & NA & 0.628 & NA & 1.447 & 2.8 & 1.534 & -1.4 & 1.7 & -0.3 & 1.714 & 4.6 & 1.684 & 2.2 \\
\hline
\end{tabular}

Abbreviation: CI, Confidence Interval; NA, Not Applicable; APC, Annual percent change based on incidence (delay adjusted) and mortality rates age adjusted to the 2000 US standard population. "The APC is significantly different from zero $(P<0.05)$.

0.087 , while the incidence rate for male breast DLBCL was 0.007 .

\section{Patient demographics and tumor characteristics}

A total of 1021 patients with breast DLBCL were identified in the SEER-18 database from 1973-2014. Breast DLBCL is generally a disease of the elderly, with $70.7 \%$ patients diagnosed at $>60$ years old. The median age was 70 years old. A predominance of patients were female (96.4\%). Whites comprised the highest proportion of patients accounting for $81.3 \%$ of cases. The right breast was as frequently involved as the left, whereas bilateral breast involvement was not common (2.6\%). Among patients for whom staging information was available, approximately $53.6 \%$ of breast DLBCL patients were categorized as stage I, and $17.5 \%$ as stage II. Surgery was used as a component of therapy in 237 patients (23.2\%). The information of demographics, tumor characteristics and surgery received were summarized in Table 2.

\section{Survival and prognostic factors}

Approximately 992 cases $(97.2 \%)$ with complete survival information were eligible for inclusion in analyses of the OS and DSS of patients with breast DLBCL. OS 
Table 2: Demographic and clinical characteristics of patients with breast and nodal DLBCL

\begin{tabular}{|c|c|c|c|c|c|}
\hline \multirow[b]{2}{*}{ Characteristic } & \multicolumn{2}{|c|}{ Breast DLBCL $(n=1021)$} & \multicolumn{2}{|c|}{ Nodal DLBCL $(n=74440)$} & \multirow[b]{2}{*}{$\boldsymbol{P}$} \\
\hline & No. of patients & Percentage (\%) & No. of patients & Percentage (\%) & \\
\hline Year of diagnosis & & & & & 0.074 \\
\hline $1973-1990$ & 99 & 9.7 & 9207 & 12.4 & \\
\hline $1991-2000$ & 200 & 19.6 & 14411 & 19.4 & \\
\hline $2001-2010$ & 483 & 47.3 & 34374 & 46.2 & \\
\hline $2011-2014$ & 239 & 23.4 & 16448 & 22.1 & \\
\hline Age & & & & & $<0.001$ \\
\hline$<50$ & 152 & 14.9 & 14629 & 19.7 & \\
\hline $50-59$ & 148 & 14.5 & 11591 & 15.6 & \\
\hline $60-69$ & 207 & 20.3 & 15865 & 21.3 & \\
\hline $70-79$ & 259 & 25.4 & 18350 & 24.7 & \\
\hline$\geq 80$ & 255 & 25 & 14005 & 18.8 & \\
\hline Sex & & & & & $<0.001$ \\
\hline Male & 37 & 3.6 & 40300 & 54.1 & \\
\hline Female & 984 & 96.4 & 34140 & 45.9 & \\
\hline Race & & & & & $<0.001$ \\
\hline White & 830 & 81.3 & 63797 & 85.7 & \\
\hline Black & 54 & 5.3 & 5334 & 7.2 & \\
\hline Other (American & 130 & 12.7 & 4959 & 6.7 & \\
\hline $\begin{array}{l}\text { Indian/AK Native, } \\
\text { Asian/Pacific Islander) }\end{array}$ & & & & & \\
\hline Asian/racinc Islander) & & & & & $<0.001$ \\
\hline Stage & & & & & \\
\hline I & 547 & 53.6 & 12111 & 16.3 & \\
\hline II & 179 & 17.5 & 12967 & 17.4 & \\
\hline III & - & - & 14687 & 19.7 & \\
\hline IV (bilateral) & 146 & 14.3 & 26301 & 35.3 & \\
\hline Unknown & 149 & 14.6 & 8374 & 11.2 & \\
\hline Tumor laterality & & & & & \\
\hline Right & 502 & 49.2 & & & \\
\hline Left & 484 & 47.4 & & & \\
\hline Bilateral & 27 & 2.6 & & & \\
\hline Surgery & & & & & $<0.001$ \\
\hline Yes & 237 & 23.2 & 11999 & 16.1 & \\
\hline No & 495 & 48.5 & 41079 & 55.2 & \\
\hline Unknown & 289 & 28.3 & 21362 & 28.7 & \\
\hline
\end{tabular}

and DSS for the entire cohort of breast DLBCL patients are presented in Figure 2A and 2B. The overall survival (OS) rates at 5, 10, 15, and 20 years for breast DLBCL was $94.6 \%, 89.7 \%, 82.5 \%$ and $75.1 \%$, whereas DSS rates at $5,10,15$, and 20 years were $94.7 \%, 87.2 \%, 79.6 \%$ and $69.6 \%$, respectively. Patients with stage I-II exhibited improved OS and DSS compared to stage IV patients (both $P<0.001$ ) (Figure 2C and 2D). Younger patients ( $<$ 70 years old) showed prolonged OS and DSS compared to elderly patients ( $\geq 70$ years old) (both $P<0.001$ ) (Figure 2E and 2F).

The OS improved significantly over time, OS for patients diagnosed in 2001 to 2010 and for patients diagnosed in 2011-2014 was both significantly improved 
compared with that of patients diagnosed in 1973 to 1990 (both $p<0.001$ ). Patients diagnosed in 2001 to 2010 exhibited prolonged DSS compared with that of patients diagnosed in 1991-2000 ( $P=0.004)$ (Figure 3A and 3B). Univariate and multivariate analyses were performed to determine independent prognostic factors predicting overall and disease-specific survival with adjustment for various clinical variables. The effects of variables on OS and DSS are listed in Table 3. Our univariate analysis revealed that older age, white races, advanced stage (IV), no surgery and diagnosis before 2000 were associated with worse overall survival. Younger age, early stage (I-II) and diagnosis after 2000 were predictors of improved DSS. In the multivariate analysis, independent predictors of better OS and DSS were younger age and early stage (I-II).

\section{Surgical intervention}

Surgical intervention changed markedly from 1991 to 2014. From 1991 to 2000, surgery was delivered to $56.8 \%$ of patients with breast DLBCL, while $43.2 \%$ patients received no surgery. By 2001 to 2010, the
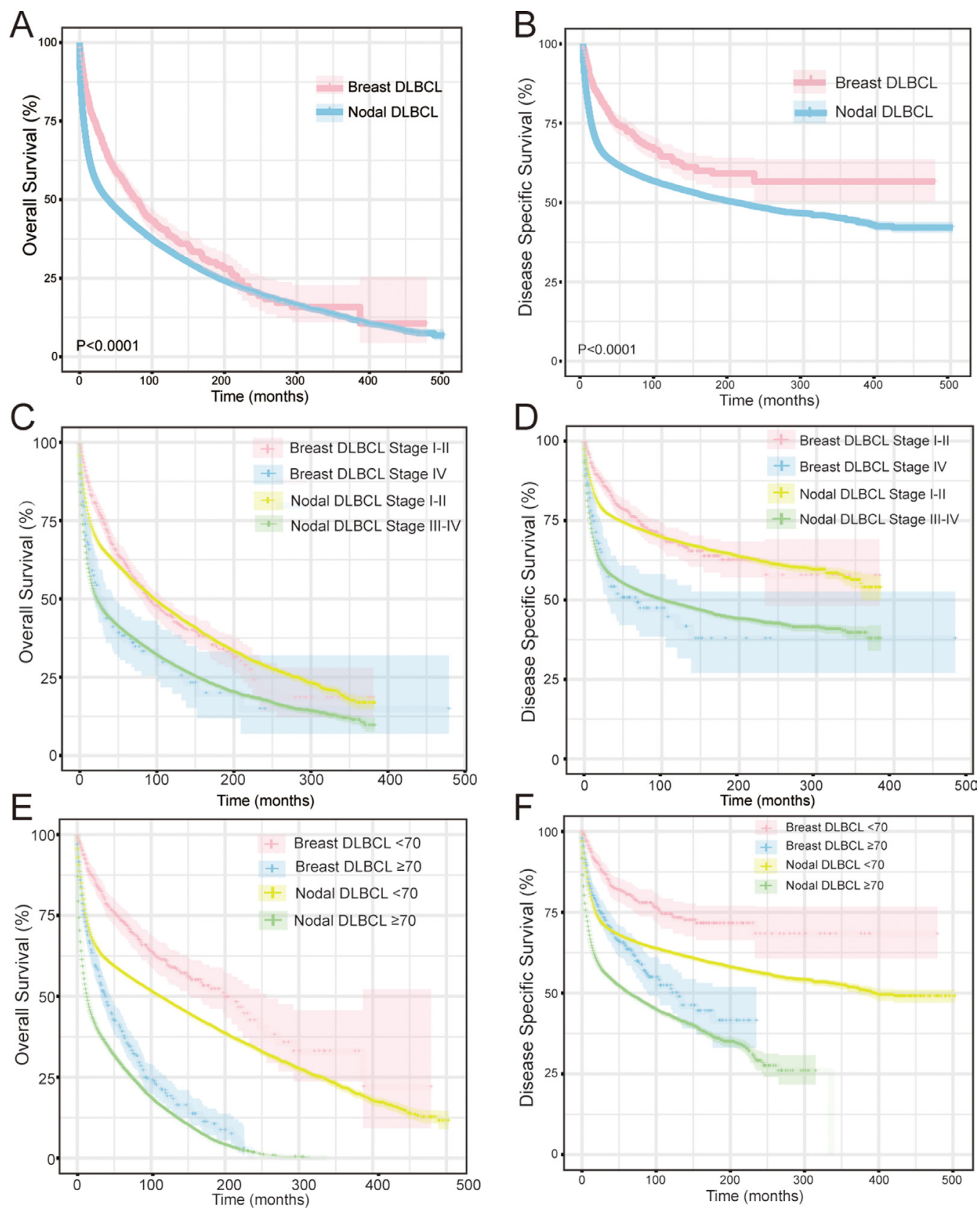

Figure 2: Comparison of overall survival (OS) and disease-specific survival (DSS) of breast DLBCL and nodal DLBCL. (A), (B): Kaplan-Meier survival curves of OS (A) and DSS (B) in breast DLBCL and nodal DLBCL. (C) (D): Kaplan-Meier survival curves of OS (C) and DSS (D) by stage (stage I-II vs stage III-IV) in breast DLBCL and nodal DLBCL. (E) (F): Kaplan-Meier survival curves of OS (E) and DSS (F) by age ( $<70$ years old vs $\geq 70$ years old) in breast DLBCL and nodal DLBCL. 
Table 3: Univariate and multivariate analyses of clinical characteristics associated with OS and DSS of patients with breast DLBCL

\begin{tabular}{|c|c|c|c|c|c|c|c|c|c|c|c|c|c|}
\hline \multirow[b]{3}{*}{ Variables } & \multicolumn{7}{|c|}{ Univariate Analysis } & \multicolumn{6}{|c|}{ Multivariate Analysis } \\
\hline & \multicolumn{4}{|c|}{ Overall Survival } & \multicolumn{3}{|c|}{ Disease-Specific Survival } & \multicolumn{3}{|c|}{ Overall Survival } & \multicolumn{3}{|c|}{ Disease-Specific Survival } \\
\hline & Median & HR & $95 \% \mathrm{CI}$ & $P$ & HR & $95 \% \mathrm{CI}$ & $P$ & HR & $95 \% \mathrm{CI}$ & $P$ & HR & $95 \%$ CI & $P$ \\
\hline \multicolumn{14}{|l|}{ Age (years) } \\
\hline$<70$ & 58 & 1 & & & 1 & & & 1 & & & 1 & & \\
\hline$\geq 70$ & 26 & 3.3 & $2.74-3.97$ & $<0.001$ & 2.33 & $1.82-2.98$ & $<0.001$ & 3.34 & $2.76-4.04$ & $<0.001$ & 2.34 & $1.82-3.00$ & $<0.001$ \\
\hline \multicolumn{14}{|l|}{ Race } \\
\hline White & 38 & 1 & & & 1 & & & 1 & & & & & \\
\hline Others & 44 & 0.711 & $0.56-0.90$ & 0.005 & 0.87 & $0.64-1.19$ & 0.382 & 0.96 & $0.75-1.48$ & 0.732 & & & \\
\hline \multicolumn{14}{|l|}{ Stage } \\
\hline I-II & 45 & 1 & & & 1 & & & 1 & & & 1 & & \\
\hline IV (bilateral) & 19.5 & 1.91 & $1.52-2.40$ & $<0.001$ & 2.58 & $1.93-3.44$ & $<0.001$ & 1.93 & $1.54-2.44$ & $<0.001$ & 2.73 & $2.04-3.65$ & $<0.001$ \\
\hline Unknown & 31 & 1.43 & $1.14-1.79$ & 0.002 & 1.16 & $0.81-1.67$ & 0.41 & 1.31 & $1.03-1.66$ & 0.028 & 1.03 & $0.71-1.50$ & 0.87 \\
\hline \multicolumn{14}{|c|}{ Tumor Laterality } \\
\hline Right & 40 & 1.04 & $0.88-1.24$ & 0.63 & 0.99 & $0.78-1.27$ & 0.96 & & & & & & \\
\hline Left & 41 & 1 & & & 1 & & & & & & & & \\
\hline Bilateral & 30 & 1.239 & $0.72-2.13$ & 0.44 & 1.61 & $0.82-3.17$ & 0.17 & & & & & & \\
\hline \multicolumn{14}{|l|}{ Surgery } \\
\hline No & 34 & 1 & & & 1 & & & 1 & & & & & \\
\hline Yes & 64.5 & 0.77 & $0.62-0.97$ & 0.025 & 0.75 & $0.54-1.04$ & 0.08 & 0.83 & $0.66-1.04$ & 0.145 & & & \\
\hline \multicolumn{14}{|c|}{ Year of diagnosis } \\
\hline $1973-1990$ & 34 & 1 & & & 1 & & & 1 & & & 1 & & \\
\hline $1991-2000$ & 62 & 0.81 & $0.62-1.06$ & 0.12 & 0.79 & $0.55-1.14$ & 0.21 & 0.86 & $0.64-1.16$ & 0.32 & 0.7 & $0.48-1.03$ & 0.067 \\
\hline 2001-2010 & 63 & 0.66 & $0.51-0.85$ & 0.001 & 0.51 & $0.36-0.73$ & $<0.001$ & 0.89 & $0.59-1.34$ & 0.578 & 0.45 & $0.31-0.64$ & $<0.001$ \\
\hline $2011-2014$ & 14 & 0.62 & $0.43-0.89$ & 0.009 & 0.48 & $0.30-0.79$ & 0.003 & 0.88 & $0.54-1.44$ & 0.619 & 0.44 & $0.27-0.72$ & 0.001 \\
\hline
\end{tabular}

proportion of patients that received surgery at diagnosis decreased to $33.0 \%$. The percentage of surgery received by breast DLBCL patients further decreased to $16.9 \%$. The rates of surgery and no surgery according to the era of diagnosis are shown in Figure 4.

Subgroup analyses were performed to determine the factors that correlated with the effect of surgical intervention and the $P$ value of overall survival (OS) and disease specific survival (DSS) comparing surgery and no surgery were listed in Table 4. Overall, the surgery group showed improved OS in patients compared to the no-surgery group $(P=0.014)$, however, there was no statistically significant difference in DSS of patients between the two groups $(P=0.057)$. Age had no effect on surgical efficacy in breast DLBCL. Breast DLBCL patients of white who underwent surgery exhibited an improved survival rate according to Log-rank analysis, but this survival benefit was not statistically significant as the $P$ value is on the critical point $(P=0.05)$. The overall survival benefit of surgery was observed in patients diagnosed between the year of 2001-2010 $(P=0.036)$. No significant survival improvement was found in the remaining cohorts with surgery.

\section{Comparison with nodal DLBCL}

Consistent with the increase in the incidence trend of breast DLBCL, nodal DLBCL has also increased in frequency during the past four decades (Figure 1B). The increase in the incidence trend could be observed in both age groups ( $<70$ and $\geq 70$ years old), females and males, and all the races (white, black and others) (Table 1). A total of 74440 patients with nodal DLBCL were identified. Patients with breast DLBCL were older, mainly women, diagnosed at earlier stages and had lower prevalence in white and black races compared with nodal DLBCL (Table 2).

Patients with breast DLBCL had better DSS than that of nodal DLBCL $(P<0.0001)$. The median OS of breast DLBCL was also better than that of nodal DLBCL for the first 18 years, although the curves with 95\%CI overlapped afterwards $(P<0.0001)$ (Figure 2A and 2B). When patients were categorized according to stage, breast DLBCL seemed to have better OS initially for I-II stage, however this advantage disappeared beyond 6 years $(P=0.118)$. Regarding DSS, breast DLBCL with stage III had a better outcome than nodal DLBCL with stage I-II 
$(P=0.041)$. There was no significant difference between nodal and breast DLBCL for advanced stage (stage III-IV in nodal DLBCL vs. Stage IV in breast DLBCL) in OS and DSS $(P=0.628$ and $P=0.969)$ (Figure 2C and 2D). When we examined survival according to age, no matter 70 years and older or 70 years younger, OS and DSS of breast DLBCL were always better than nodal DLBCL (all $P<0.001$ ) (Figure $2 \mathrm{E}$ and $2 \mathrm{~F}$ )

When analyzing survival of nodal DLBCL by the era of diagnosis, we found that OS and DSS improved significantly over time which is more obvious than breast DLBCL. OS and DSS for patients diagnosed in 1991 to 2000 was significantly improved compared with that of patients diagnosed in 1973 to 1990. Patients diagnosed in 2001 to 2010 exhibited prolonged OS and DSS compared with that of patients diagnosed in 1991 to 2000. Significant OS and DSS improvements was also found in patients diagnosed in 2011 to 2014 and patients diagnosed in 1991 to 2000 (all $P<0.001$ ). (Figure 3C and 3D).

\section{DISCUSSION}

To our knowledge, this is the first epidemiological study and the largest population-based study describing the incidence, characteristics and management of breast
DLBCL in the United States based on the SEER database. There has been a similar study from United States [16], however their eligibility included all types of breast lymphoma and investigated mainly on their incidences and survivals. We retrieved the newest data released on 28/4/2017 and included the patients diagnosed from the year of 1973 to 2014. We focused on breast DLBCL, which is the most frequent subtype of breast lymphoma and expanded on their work to study breast DLBCL in several ways, such as baseline characteristics, prognostic factors, comparison with nodal DLBCL as well as the role that surgery plays in the treatment of breast DLBCL.

Several important conclusions can be derived based on our results. We observed that the incidence rate of breast DLBCL, especially in whites $(\mathrm{APC}=3.0 ; 95 \%$ $\mathrm{CI}=2.1-3.8)$, is increasing overtime, which may be partly due to the increased awareness of the disease as a unique entity by pathologists and clinicians over time. Likewise, we also found a similar increase in the incidence trend of nodal DLBCL.

Consistent with previous studies [6,17], our study indicates a nearly exclusive incidence in females. It suggests a potential role for sex hormones in the pathogenesis of primary breast lymphoma. Epidemiological data suggested that estrogen was a risk factor for lymphoma
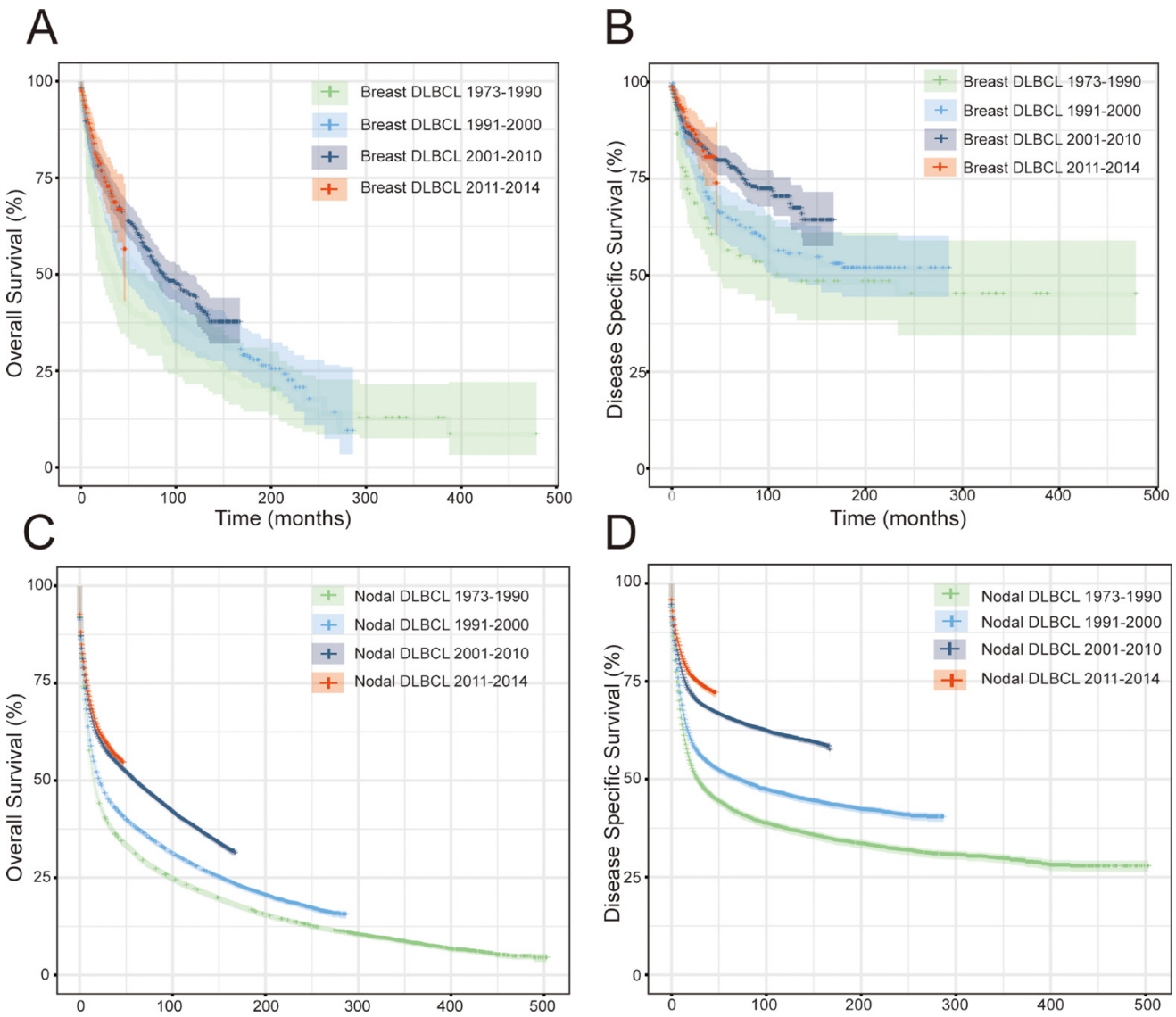

Figure 3: OS and DSS of breast DLBCL and nodal DLBCL according to era of diagnosis (1973-1990, 1991-2000, 2001-2010, and 2011-2014). 
Table 4: Analysis of effects of surgical treatment on OS and DSS

\begin{tabular}{|c|c|c|c|c|c|c|}
\hline & \multicolumn{2}{|c|}{ Surgery } & \multicolumn{2}{|c|}{ No Surgery } & \multirow{2}{*}{$\frac{\text { Overall survival }}{P \text { value }}$} & \multirow{2}{*}{$\begin{array}{c}\begin{array}{c}\text { Disease-specific } \\
\text { survival }\end{array} \\
P \text { value }\end{array}$} \\
\hline & No. of patients & Median Months & No. of patients & Median Months & & \\
\hline All & 248 & 64.5 & 556 & 34 & 0.014 & 0.057 \\
\hline \multicolumn{7}{|l|}{ Age } \\
\hline$<70$ & 128 & 98.5 & 278 & 40 & 0.144 & 0.068 \\
\hline$\geq 70$ & 120 & 41.5 & 278 & 20 & 0.12 & 0.433 \\
\hline \multicolumn{7}{|l|}{ Race } \\
\hline White & 196 & 65.5 & 456 & 34 & 0.05 & 0.067 \\
\hline Others & 52 & 58.5 & 100 & 34 & 0.137 & 0.589 \\
\hline \multicolumn{7}{|l|}{ Stage } \\
\hline I-II & 197 & 70 & 388 & 39 & 0.224 & 0.246 \\
\hline IV (bilateral) & 25 & 30 & 97 & 16 & 0.174 & 0.218 \\
\hline \multicolumn{7}{|l|}{ Tumor Laterality } \\
\hline Right & 116 & 62 & 275 & 33 & 0.463 & 0.061 \\
\hline Left & 128 & 69 & 257 & 35 & 0.946 & 0.503 \\
\hline Bilateral & 4 & 51 & 18 & 15 & 0.958 & 0.641 \\
\hline \multicolumn{7}{|l|}{ Year of diagnosis } \\
\hline 1973-1990 & 0 & NA & 0 & NA & NA & NA \\
\hline 1991-2000 & 50 & 110 & 38 & 67 & 0.14 & 0.396 \\
\hline $2001-2010$ & 158 & 77 & 321 & 58 & 0.036 & 0.08 \\
\hline 2011-2014 & 40 & 16.5 & 197 & 13 & 0.8 & 0.38 \\
\hline
\end{tabular}

[18-20], and a recent large study found that women treated with estrogen hormone replacement therapy had 29\% increased risk of developing non-Hodgkin's lymphoma (not specifically primary breast lymphoma) compared with women that never exposed to [21].

Bilateral involvement of the breast appears to be a feature of aggressive disease with poor prognosis [9, 22]. Previously published studies $[9,23]$ reported a right-sided predisposition for breast DLBCL. As the cohort became larger, the right-sided predominance became less apparent. In our study, we showed balanced laterality of breast involvement at the time of diagnosis (right: left $=1.04: 1$ ). We also observed that $2.6 \%$ patients were diagnosed with bilateral breast DLBCL, which is consistent with the other two reports that showed involvement of bilateral breast in $1 \%$ and $5 \%$ patients $[9,23]$.

Age at diagnosis was an important predictor of survival in the multivariate analysis and younger patients ( $<70$ year old ) exhibited improved survival outcomes. This findings could be observed in both breast and nodal DLBCL. Early tumor stage was also associated with improved survival in breast DLBCL as well as nodal DLBCL. Univariate analysis also showed significant OS benefits in non-white races and surgery group, however, the benefits were lost in multivariate analysis. It is unclear whether this observation is due to distinct tumor biology or to socioeconomic factors, further investigation is needed.

Increasing trends of overall survival and diseasespecific survival were observed over time, which may be due to improvements in the comprehensive approach of treatment. Particularly, the rapidly developing targeted therapy for CD20-positive B lymphoma has further improved survival in patients with lymphoma [24-27, 35]. Data from our study also provided a comparison of the treatment of breast DLBCL before and after the rituximab era in a population. We found a significant improvement in DSS for breast DLBCL and in both OS and DSS for nodal DLBCL after the introduction of rituximab.

As the rarity of breast DLBCL, data are limited. With the rise of breast DLBCL, management strategies have been revisited. However, the treatment recommendations are difficult to make and the role of surgery in this comprehensive breast DLBCL therapy strategy is still subject to debate. Excisional biopsy should be performed to facilitate correct diagnosis. Although fine needle aspiration may differentiate carcinoma from lymphoma, it lacks details that are necessary to accurately classify subtypes of NHL and thus is insufficient as a diagnostic procedure [30]. Previous data showed that surgical resection results in inferior local control [19], and some studies demonstrated that treatment including mastectomy is associated with higher all-cause and disease-specific mortality $[9,14,31]$. Our results showed that the proportions of patients received surgery decreased over time. This may be largely due to complications of surgery which leads to higher mortality $[9,14,31]$, and the use of anthracyclines-based chemotherapy and rituximab which have been shown to have a beneficial effect on PFS 
and $\operatorname{OS}[1,9,24-29,32,35]$. In the present results, an OS benefit from surgery was noted in overall patients, but the benefit of DSS was lost. Patients diagnosed between the year of 2001 to 2010 with surgery showed improved overall survival compared with no surgery group. A possible and plausible explanation for this finding is that patients who had surgery might have received combined therapy that involves chemotherapy and radiotherapy which is a current treatment approach for DLBCL. When analyzed according to age, stage, race, tumor laterality, year of diagnosis, the overall survival benefit of surgery could only be found in patients diagnosed between the year of 2001-2010 $(P=0.036)$. No OS or DSS benefit of surgery was observed in other groups. Thus surgical intervention beyond excisional biopsy was not recommended.

We found that as a group, breast DLBCL had a better OS and DSS. The major reason for this finding may be that breast DLBCL predominantly presents as early stage disease compare with nodal DLBCL (71.1\% vs 33.4\%). As most lesions of breast DLBCL are in superficial anatomic location, they can be detected by screening mammography in an early phase. This could also be explained by the our results that no OS advantage in patients with I-II stage breast DLBCL was found compared to their nodal counterparts when patients were categorized according to stage. The distinction of clinical characteristics between breast DLBCL and nodal DLBCL could be observed in our study. Classification and management of breast DLBCL may be revisited as an entity, similar to CNS and cutaneous DLBCL.

There are several potential limitations to consider with the present study. Firstly, the treatment information that is available is limited to surgery, since SEER-18 released on 28/4/2017 also lacks information on the use of radiotherapy and chemotherapy. It was not possible to know what proportions of patients actually received anthracycline-based chemotherapy, rituximab and CNS prophylaxis now routinely used in clinical practice of DLBCL. As a result, several potential prognostic factors were not considered in this analysis. However, based on our clinical practice and previous published data [23], it is plausible to speculate that most patients did undergo some form of chemotherapy appropriate for DLBCL and many, if not most, patients did receive immunochemotherapy with rituximab. Secondly, although SEER has strict categorization guidelines, the stage information of some patients may be wrong. However, most of the patients were staged correctly, since the number of patients with stage III and nonbilateral stage IV was limited. Those cases were excluded from our analyses. Thirdly, detailed information on the type of surgery performed, margin status, peri-operative complications is not available in SEER database. Furthermore, the inherent limitations of using a population-based database including variations in data reporting and coding system, patient migration, and

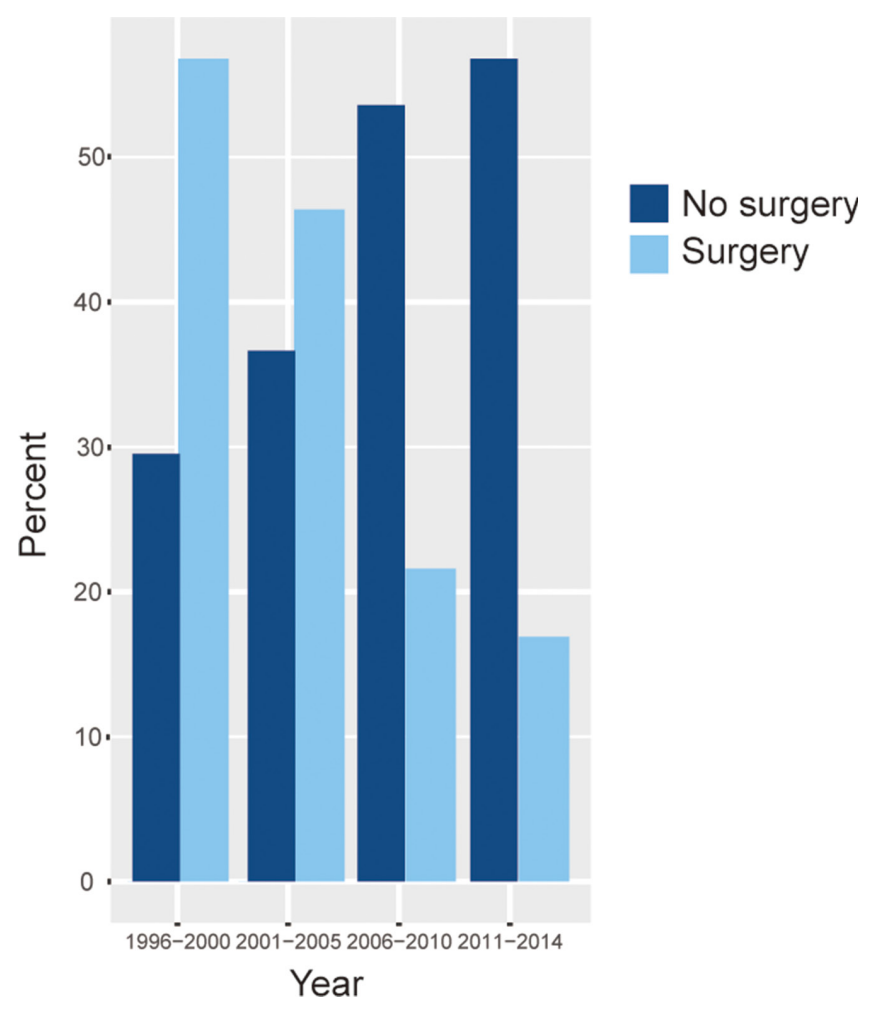

Figure 4: The proportions of patients with breast DLBCL that received surgery and no surgery over time.Y axis indicates percentage of patients $(\%)$, and $X$ axis indicates the year of diagnosis (1996-2000, 2001-2005, 2006-2010 and 2011-2014). 
selection bias, might potentially exist in this study. Given above, the results of this analysis should be interpreted with caution. Despite these limitations, SEER database remains a valuable source in studying such kind of rare cancers. This study can still offer important insights for breast DLBCL, and provide useful information on baseline characteristics and outcomes.

Prospective studies should be performed to confirm these findings and future work in a multinational collaborative way is needed to advance our understanding of the etiology and biology for this rare malignancy. Results can then be used to develop evidence-based treatment recommendations and guidelines for clinical practitioners.

\section{MATERIALS AND METHODS}

National Cancer Institute's Surveillance, Epidemiology, and End Results (SEER) database collects and publishes cancer incidence and survival data from population-based cancer registries covering approximately $28 \%$ of the US population [15]. Nine registries including Atlanta, Connecticut, Detroit, Hawaii, Iowa, New Mexico, San Francisco-Oakland, Seattle-Puget Sound, and Utah were included in SEER-9 before 1992. Since 1992, nine more registries were added sequentially overtime, including Los Angeles, San Jose-Monterey, Rural Georgia, the Alaska Native Tumor Registry, Greater California, Kentucky, Louisiana, New Jersey and Greater Georgia to become the current SEER-18. We queried SEER-18 Registries Research Data, Nov 2016 (released on 28/4/2017) using SEER Stat 8.3.4 software (National Cancer Institute, Bethesda, MD; available at http://seer.cancer.gov/seerstat/) (accessed May 2017) and identified patients diagnosed with DLBCL with breast or lymph node listed as the primary site. International Classification of Disease for Oncology, third edition histology codes (ICD-O-3) for DLBCL (9680, 9675, 9684) were used to identify all patients with DLBCL. Codes C50.0-50.9 and codes C77.0-C77.9 were used to identify patients with breast or lymph nodes as the primary site, respectively. Patients were excluded if diagnosis was made on the death certificate or at autopsy. Data on patient demographics, stage at diagnosis, laterality of breast involvement, treatment of surgery or radiotherapy received, survival data, and cause of death were extracted from this database. There is no data available in SEER regarding the use of chemotherapy or indications for surgery. Patient characteristics were summarized using descriptive statistics and continuous variables were converted into categorical variables including age and year of diagnosis. Tumors were staged according to the Ann Arbor Stage classification for lymphoma [33]. Differences in demographics and tumor characteristics between nodal and breast DLBCL were examined using the Pearson Chisquare test and the Wilcoxon rank sum test.
All population rates are age-adjusted to the standard population of the United States in 2000. Age-adjusted incidence rate calculations were obtained from SEER-9 database (released in April 2017) and were analyzed using the SEER Stat 8.3.4. The data was expressed per 100,000 persons.

The advent of therapeutic monoclonal antibodies such as rituximab, which is approved by FDA in 1997, has increased the effectiveness of treatment for Non-Hodgkin's lymphoma [34]. The standard of care for DLBCL which is the combination of rituximab, cyclophosphamide, doxorubicin, vincristine and prednisone was established by Coiffier B et al. from Hospices Civils de Lyon and the Université Claude Bernard in France and their study results were first presented as an abstract in December 2000 at the American Society of Hematology annual meeting [35]. As a result, we used the year of 2000 as cutoff point when we studied the potential impact of the introduction of rituximab on survival.

We partitioned surgical interventions into surgery and no surgery, to investigate the relationship between surgery and survival outcomes.

Follow-up data were up to date until 2014. Survival data was analyzed according to overall survival (OS), disease-specific survival (DSS) using Kaplan-Meier method and survival curves were constructed based on primary sites, age at diagnosis, Ann Arbor Stage and year of diagnosis. Univariate analysis using Cox-proportional hazards model was performed to evaluate the association between variables and OS/DSS. Statistically significant covariates identified in univariate analyses were included in multivariate models.

Statistical analysis was performed using SPSS statistical software version 20.0 (SPSS Inc., IBM Corporation, Chicago, IL, USA) and R version 3.3.3 Software (R Foundation for Statistical Computing, Vienna, Austria; available from http:/www.r-project. org/index.html ). $P$-values $<0.05$ were considered statistically significant. All confidence intervals were set as $95 \%$ CI.

\section{ACKNOWLEDGMENTS}

The work was supported by the National Natural Science Foundation of China (No. 81470353), Science and Technology commission of Shanghai Municipality (15495810300), Shanghai hospital development center Emerging advanced technology joint research project (SHDC 12014105) and Shanghai Municipal Commission of Health and Family Planning (2015ZB0204).

\section{CONFLICTS OF INTEREST}

The authors indicated no potential conflicts of interest. 


\section{REFERENCES}

1. Aviv A, Tadmor T, Polliack A. Primary diffuse large B-cell lymphoma of the breast: looking at pathogenesis, clinical issues and therapeutic options. Ann Oncol. 2013; 24:2236-2244.

2. Surov A, Holzhausen HJ, Wienke A, Schmidt J, Thomssen C, Amold D, Ruschke K, Spielmann RP. Primary and secondary breast lymphoma: prevalence, clinical signs and radiological features. Br J Radiol. 2012;85:e195-e205.

3. Wiseman C, Liao K. Primary lymphoma of the breast. Cancer. 1972; 29:1705-12.

4. Anne N, Pallapothu R. Lymphoma of the breast: a mimic of inflammatory breast cancer. World J Surg Oncol. 2011; 9:125.

5. Mazellier S, Hubiche T, Weinbreck N, Gutnecht J, Del GP. Erysipeloid Hodgkin lymphoma. Eur J Dermatol. 2014; 24:513-4.

6. Stasi R, Evangelista ML, Brunetti M, Bussa S, Maritati R, Turrini L, Taccogna S, Crescenzi A, Angelini F. Analysis of differential therapeutic strategies for primary breast lymphoma: two case reports. Medical Oncology. 2009; 26:22-6.

7. Yang H, Lang RG, Fu L. Primary breast lymphoma (PBL): A literature review. Clin Oncol Cancer Res. 2011; 8:128-32.

8. Domchek SM, Hecht JL, Fleming MD, Pinkus GS, Canellos GP. Lymphomas of the breast: primary and secondary involvement. Cancer. 2002; 94:6-13

9. Ryan G, Martinelli G, Kuper-Hommel M, Tsang R, Pruneri G, Yuen K, Roos D, Lennard A, Devizzi L, Crabb S, Hossfeld D, Pratt G, Dell'Olio M. Primary diffuse large B-cell lymphoma of the breast: prognostic factors and outcomes of a study by the International Extranodal Lymphoma Study Group. Ann Oncol. 2008;19: 233-41.

10. Talwalkar SS, Miranda RN, Valbuena JR, Routbort MJ, Martin AW, Medeiros LJ. Lymphomas involving the breast: a study of 106 cases comparing localized and disseminated neoplasms. Am J Surg Pathol. 2008; 32:1299-309.

11. Uesato M, Miyazawa Y, Gunji Y, Ochiai T. Primary nonHodgkin's lymphoma of the breast: report of a case with special reference to 380 cases in the Japanese literature. Breast Cancer. 2005; 12:154-8.

12. Validire P, Capovilla M, Asselain B, Kirova Y, Goudefroye R, Plancher C, Fourguet A, Zanni M, Gaulard P, Vincent-Salomon A, Decaudin D. Primary breast nonHodgkin's lymphoma: a large single center study of initial characteristics, natural history, and prognostic factors. Am J Hematol. 2010; 84:133-9.

13. Inic Z, Inic M, Zegarac M, Inic I, Pupic G. Three cases of combined therapy in primary breast lymphoma (PBL) with successful outcomes. Clin Med Insights Oncol. 2013; 7: 159-63.

14. Jennings WC, Baker RS, Murray SS, Howard CA, Parker DE, Peabody LF. Primary breast lymphoma: the role of mastectomy and the importance of lymph node status. Ann Surg. 2007; 245:784-9.
15. National Cancer Institute. Surveillance, Epidemiology and End Results (SEER) Program. Available at www.seer.cancer.gov.

16. Thomas A, Link BK, Altekruse S, Romitti PA, Schroeder MC. Primary breast lymphoma in the United States: 19752013. J Natl Cancer Inst. 2017; 109.

17. Radkani P, Joshi D, Paramo JC, Mesko TW. Primary breast lymphoma: 30 years of experience with diagnosis and treatment at a single medical center. JAMA Surg. 2014; 149:91-3.

18. Norgaard M, Poulsen AH, Pedersen L, Gregersen H, Friis S, Ewertz M, Johnsen HE, Sorensen HT. Use of postmenopausal hormone replacement therapy and risk of non-Hodgkin's lymphoma: a Danish population-based cohort study. Br J Cancer. 2006; 94:1339-41.

19. Mildon KH, Ansell P, Roman E, Kane EV. Reproductive factors, menopausal hormone therapy, and risk of nonHodgkin, diffuse large B-cell and follicular lymphomas: a UK case-control study. Cancer Causes Control. 2010; 21:2079-83.

20. Fernandez E, Gallus S, Bosetti C, Franceschi S, Negri E, La Vecchia C. Hormone replacement therapy and cancer risk: a systematic analysis from a network of case-control studies. Int J Cancer. 2003; 105:408-12.

21. Teras LR, Patel AV, Hildebrand JS, Gapstur SM. Postmenopausal unopposed estrogen and estrogen plus progestin use and risk of non-Hodgkin lymphoma in the American Cancer Society Cancer Prevention Study-II Cohort. Leuk Lymphoma. 2013; 54:720-5.

22. Guo HY, Zhao XM, Li J, Hu XC. Primary non-Hodgkin's lymphoma of the breast: eight-year follow-up experience. Int J Hematol. 2008; 87:491-7.

23. Hosein PJ, Maragulia JC, Salzberg MP, Press OW, Habermann TM, Vose JM, Bast M, Advani RH, Tibshirani R, Evens AM, Islam N, Leonard JP, Martin P. A multicentre study of primary breast diffuse large B-cell lymphoma in the rituximab era. Br J Haematol. 2014; 165:358-363.

24. Czuczman MS, Grillo-Lopez AJ, White CA, Saleh M, Gordon L, LoBuqlio AF, Jonas C, Klippenstein D, Dallaire B, Vams C. Treatment of patients with low-grade B-cell lymphoma with the combination of chimeric anti-CD20 monoclonal antibody and CHOP chemotherapy. J Clin Oncol. 1999; 17:268-276.

25. Sehn LH, Donaldson J, Chhanabhai M, Fitzgerald C, Gill K, Klasa R, MacPherson N, O'Reilly S, Spinelli JJ, Sutherland J, Wilson KS, Gascoyne RD, Connors JM. Introduction of combined CHOP plus rituximab therapy dramatically improved outcome of diffuse large B-cell lymphoma in British Columbia. J Clin Oncol. 2005; 23:5027-5033.

26. Habermann TM, Weller EA, Morrison VA, Gascoyne RD, Cassileth PA, Cohn JB, Dakhil SR, Woda B, Fisher RI, Peterson BA, Horning SJ. Rituximab-CHOP versus CHOP alone or with maintenance rituximab in older patients with diffuse large B-cell lymphoma. J Clin Oncol. 2006; 24:3121-3127.

27. Persky DO, Unger JM, Spier CM, Stea B, LeBlanc M, McCarty MJ, Rimsza LM, Fisher RI, Miller TP; Southwest 
Oncology Group. Phase II study of rituximab plus three cycles of CHOP and involved-field radiotherapy for patients with limited-stage aggressive B-cell lymphoma: Southwest Oncology Group study 0014. J Clin Oncol. 2008; 26:2258-2263.

28. Pettengell R, Linch D, Haemato-Oncology Task Force of the British Committee for Standards in H. Position paper on the therapeutic use of rituximab in CD20-positive diffuse large B-cell non-Hodgkin's lymphoma. British journal of haematology. 2003; 121:44-48.

29. Pfreundschuh M, Trumper L, Osterborg A, Pettengell R, Trneny M, Imrie K, Ma D, Gill D, Walewski J, Zinzani PL, Stahel R, Kvaloy S, Shpilberg O, et al. CHOPlike chemotherapy plus rituximab versus CHOP-like chemotherapy alone in young patients with good-prognosis diffuse large-B-cell lymphoma: a randomised controlled trial by the MabThera International Trial (MInT) Group. Lancet Oncology. 2006; 7:379-391.

30. Cheah CY, Campbell BA, Seymour JF. Primary breast lymphoma. Cancer Treat Rev. 2014; 40:900-8.
31. Jeanneret-Sozzi W, Taghian A, Epelbaum R, Poortmans P, Zwahlen D, Amsler B, Villette S, Belkacemi Y, Nguyen T, Scalliet P, Maingon P, Gutierrez C, Gastelblum P, et al. Primary breast lymphoma: patient profile, outcome and prognostic factors. A multicentre Rare Cancer Network study. BMC Cancer. 2008; 8:1471-2407.

32. Winter MC, Hancock BW. Ten years of rituximab in NHL. Expert Opin Drug Saf. 2009; 8:223-235.

33. Moormeier JA, Williams SF, Golomb HM. The staging of non-Hodgkin's lymphomas. Semin Oncol. 1990; 17:43.

34. Coffey J, Hodgson D, Gospodarowicz MK. Therapy of nonHodgkin's lymphoma. Eur J Nucl Med Mol Imaging. 2003; 30:S28-S36.

35. Coiffier B, Lepage E, Briere J, Herbrecht R, Tilly H, Bouabdallah R, Morel P, Van Den Neste E, Salles G, Gaulard P, Reyes F, Lederlin P, Gisselbrecht C. CHOP chemotherapy plus rituximab compared with $\mathrm{CHOP}$ alone in elderly patients with diffuse large-B-cell lymphoma. N Engl J Med. 2002; 346:235-242. 